\title{
Mental Illness Prevalence and Disparities Among Hurricane Sandy Survivors: A 2-Year Retrospective - Erratum
}

Chenyi Ma; Tony Edward Smith; Roberta Rehner Iversen

doi: 10.1017/dmp.2020.46, Published online by Cambridge University Press, 28 April 2020.

Key Words: disaster, mental illness, racial disparity, social support, social trust, erratum

I

$\mathrm{n}$ the original publication of this article ${ }^{1}$, author Smith's affiliation was incomplete. The complete affiliation is as follows: Department of Electrical and Systems Engineering, University of Pennsylvania, Philadelphia, PA.

\section{Reference}

1. Ma C, Smith TE, Iversen RR. Mental illness prevalence and disparities among Hurricane Sandy survivors: a two-year retrospective. Disaster Med Public Health Preparedness. 2020. doi: 10.1017/ dmp.2020.46.

The publisher apologizes for the error. 